\title{
A política pendular de D. Fernando I de Portugal (1367-1383) e sua relação com o Cisma do Ocidente (1378-1383)
}

Leonardo Girardi ${ }^{1}$

RESUMO: Inserido no conjunto maior constituído pela Guerra dos Cem Anos, o Cisma do Ocidente (1378-1417) se caracterizará sobretudo pelo rompimento do ideal unitário representado pela Cristandade Latina - através da criação de duas Sés Pontifícias - e pelo acirramento da guerra. Assim, veremos seus efeitos por todos os reinos cristão latinos, inclusive Portugal, que no momento era governado por D. Fernando I (1367-1383). Este irá desenvolver uma política denominada pela historiografia como "pendular", por conta de suas idas e vindas entre um e outro partido originado com a guerra e o Cisma - tendo em vista a série de eventos que ocorriam na Península Ibérica, sobretudo baseados em Castela, e nos interesses internos do reino. Sendo assim, intentamos analisar detidamente como se dá esta política, de que forma se relaciona com o Cisma do Ocidente, seus desdobramentos e consequências, tanto no âmbito externo quanto interno português ao longo do reinado fernandino.

Palavras-chave: Século XIV; Guerra dos Cem Anos; Cisma do Ocidente; Portugal; D. Fernando I; política pendular.

\footnotetext{
Aluno de graduação do curso História - Licenciatura e Bacharelado, da Universidade Federal do Paraná (UFPR). Bolsista de Iniciação Científica do programa PIBIC/CNPq.
} 
Cadernos de Clio, Curitiba, n. ${ }^{\circ}$ 3, 2012

Quando tratamos da Baixa Idade Média, e mais especificamente, do século XIV, é comum nos depararmos com a clássica visão exposta de maneira geral pela historiografia como sendo este século caracterizado pela crise, motivada por conta da série de eventos de grandes proporções que infligiram a Cristandade latina severos golpes que abalariam suas estruturas. Dentro desta conjectura, podemos aqui assinalar os longos períodos de fome, a Peste Negra, e principalmente, a Guerra dos Cem Anos (PEDRERO-SÁNCHEZ, 2000). Este último evento, que irá se desenrolar de maneira intermitente ao longo do século XIV até alcançar seu término já em meados do seguinte - tendo como data canônica o ano de 1453 - será responsável por mudanças em todas as esferas da sociedade europeia medieval, desde a política até a cultura, fundando e dando base para os pilares que sustentarão a Era Moderna.

Inserido no plano maior deste evento, representado pela guerra, irá se desenvolver outro evento de igual magnitude ou tão grande quanto, conhecido como o Grande Cisma do Ocidente (1378-1417), responsável pelo rompimento do ideal unitário constituído pela ideia de Cristandade, bem como pelo acirramento dos conflitos em que estarão mergulhados os diversos reinos cristãos (FERNANDES, 2007). Ao seu término, notadamente consequências profundas irão se refletir na constituição geral da Igreja, tanto em sua organização interna e externa (neste sentido, no 
Cadernos de Clio, Curitiba, n. ${ }^{\text {o }}$ 3, 2012

que tange à sua influência sobre o domínio do poder espiritual), como na própria forma como a sociedade encarará a espiritualidade, abalada com os desenlaces do Cisma. Para tanto, faz-se necessário que tratemos um pouco mais deste momento.

O regresso à Roma do Papa Gregório XI no ano de 1377 é tido como uma iniciativa corajosa da parte do Pontífice, principalmente por dar fim ao período compreendido como o "Exílio de Avinhão", além de possibilitar ao Papado o resgate de parte da autonomia que gozava antes dos reveses causados após a morte do Papa Bonifácio VIII. Entretanto, um ano transcorrido após sua chegada Gregório XI vem a falecer, levando os cardeais a uma eleição rápida e conturbada que colocará no Trono de São Pedro o arcebispo de Bari, Bartolomeo Prigano, sob o nome de Urbano VI. Quatro meses depois da escolha de Urbano VI, nova eleição é realizada por um grupo de cardeais dissidentes (em Agnani, Itália) que por maioria de votos, declara como sendo nula sua posse. No seguimento, a 20 de setembro de 1378, desta vez na cidade de Fondi, o cardeal de Genebra, Roberto, é eleito Papa sob o nome de

${ }^{2}$ O Exílio de Avinhão compreende o período de cerca de setenta anos (13091378) em que a Cúria Pontifícia esteve ausente da Cidade Eterna, causada por sua transferência para a cidade francesa de Avinhão, fazendo com que dessa forma $o$ Papado se mantivesse sob a tutela dos soberanos franceses, além de dar fim às suas pretensões de concretizar a Teocracia Pontifícia. Por outro lado, Avinhão tornou-se um importante centro cultural, tornando-se ponto de parada nas rotas que perpassavam a Cristandade latina; por consequência, desenvolveu-se ali uma grande e opulenta corte, com um aparato administrativo/burocrático tão desenvolvido quanto aquele outrora encontrado em Roma (KNOWLES \& OBOLENKSI, 1983). 
Cadernos de Clio, Curitiba, n. ${ }^{\circ}$ 3, 2012

Clemente $\mathrm{VII}^{3}$. Como primeira iniciativa, este, muda a Cúria Pontifícia para Avinhão, dado que sua eleição acaba sendo invalidada em Roma por Urbano VI que ao mesmo tempo recusa-se a abandonar seu cargo. Instala-se assim o Cisma do Ocidente, evento que até o Concílio de Constança, convocado pelo então Imperador Sigismundo e finalmente encerrado em 1417, irá deixar a Cristandade dividida entre duas Sés Pontifícias, uma localizada em Avinhão e a outra, em Roma, vindo a agravar-se mais com a eleição de um terceiro Papa por ocasião do Concílio de Pisa, em 1409 (KNOWLES \& OBOLENSKI, 1983).

A importância do Cisma do Ocidente na Guerra dos Cem Anos se dá pela divisão da Cristandade latina em dois eixos, cada qual liderado por uma das duas grandes "potências" belicosas da época: Inglaterra e França. A rivalidade anglo-francesa refletir-se-á na escolha em que cada um desses eixos constituídos terá com relação a uma Sé Pontifícia - Inglaterra virá a se posicionar a favor de Roma e do Papa Urbano VI, em contrapartida ao reino de

\footnotetext{
${ }^{3}$ Há controvérsias acerca das motivações que levaram à anulação da eleição de 1378. Urbano VI foi eleito e reconhecido da maneira tradicional e legitima pelos cardeais. Porém, diz-se que estes sofreram a pressão do povo de Roma (em especial das grandes famílias da cidade) que exigia um Papa romano (ou que ao menos fosse italiano), além da fixação definitiva da Cúria novamente na Cidade Eterna. Em sua obra, Fortunato de Almeida, (ALMEIDA, 1967: 375) levanta duas justificativas que culminaram na decisão: a exposta por D. Rodrigo da Cunha, que remete-se ao mau comportamento do Papa, e a de Fr. Manuel dos Santos, que coloca Urbano VI como um homem digno e integro mas, apresenta como problema os cardeais, novos e acostumados com as "regalias" de Avinhão e não com um Papa rígido tal como Urbano VI.
} 
Cadernos de Clio, Curitiba, n. ${ }^{\text {o } 3,} 2012$

França, que permanecerá fiel à causa de Avinhão e de Clemente VII. Como o conflito tomará maiores proporções, aderirão a cada um dos blocos outros reinos cristãos, tendo intrínseco a essas opções seus interesses próprios, aprofundando mais as querelas movidas pela Guerra dos Cem Anos. Assim contextualizada a Europa em sua dimensão macro durante a segunda metade do século XIV, voltamos o foco de nossa discussão para a Península Ibérica, mais propriamente para o reino de Portugal, que terá uma atuação política singular frente a essa série de eventos.

A época do início do Cisma, cingia a coroa de Portugal D. Fernando I. Nascido a 31 de outubro de 1345 em Coimbra, aos vinte e um anos ascendeu ao trono, herdando um reino com os cofres cheios e em estado de relativa paz. Embora o fenômeno de crises econômicas e sociais comum a todos os reinos latinos também tivesse seus reflexos na Península Ibérica, “[...] Portugal iria ter um bom reinado: rei dado ao trato com a nobreza, augúrio de paz interna, e neutral nos negócios de Castela, promessa de paz com os vizinhos" (SOUZA, 1993: 490). Entretanto, dois problemas reverteram às premissas deste quadro: o assassinato de Pedro I, o Cruel, rei de Castela em 1369 por Henrique Trastâmara e, o fato de o próprio soberano ser solteiro ao momento em que assumiu o trono, vindo a contrair matrimônio em segredo no ano de $1371 \mathrm{com}$ Leonor Teles e o tornando público em 1372, motivo que levou seus súditos ao descontentamento e trouxe julgamentos como sendo 
Cadernos de Clio, Curitiba, n. ${ }^{\circ}$ 3, 2012

temerário, imprudente e mesmo egoísta - numa época em que os casamentos arranjados eram importantes instrumentos políticos, afetando diretamente a vida de um reino.

A sucessão da coroa castelhana foi o evento que mais teve repercussão e influência sobre Portugal. Com a ascensão ao trono do regicida Trastâmara, aclamado como Henrique II Trastâmara elaboram-se três guerras entre Castela e Portugal - o conjunto que formará as guerras fernandinas - estas respectivamente em 13691370, 1372-1373 e 1381-1382. Iniciarão os conflitos quando da intervenção portuguesa, sobre a alegação de parentesco entre Pedro I, o Cruel e D. Fernando, bisneto legítimo de Sancho IV e por conta disso, tendo por direito o trono castelhano, ao contrário de um usurpador e bastardo. Além destes motivos, o soberano português foi impelido a desembainhar sua espada pela pressão das cidades, vilas, fidalgos e prelados, culminando numa vitória portuguesa no campo de batalha (Castela estava cercada por inúmeras frentes de conflito) mas, num tratado de paz $^{4}$, provavelmente influenciado pela decisão de conselhos políticos, cientes dos movimentos ocasionados pela Guerra dos Cem Anos; nesse sentido, temos a vitória do bloco franco-castelhano, cujas negociações de paz foram conduzidas pelo reino de França e pelo Papa.

${ }^{4}$ A Paz de Alcoutim, selada em março de 1371. 
Cadernos de Clio, Curitiba, n. ${ }^{\text {o }}$ 3, 2012

Realizado enlace matrimonial entre D. Fernando e Leonor Teles, o tratado de paz anteriormente estabelecido é rompido, bem como o Acordo de Tui (1372), que definia a ampliação das fronteiras do reino a norte e leste como resultado da guerra. Em julho de 1372, é estabelecido o Tratado de Tagilde, através do qual D. Fernando irá tomar o partido do reino de Inglaterra contra Henrique II e seus aliados franceses. Muito embora este tratado só tenha sido ratificado com Eduardo III em 1373, o mesmo foi visto pelos castelhanos como um claro alinhamento português ao lado de seu inimigo. Face às ações que denotavam tal prerrogativa, Henrique II decide invadir Portugal em dezembro de 1372, marchando para Lisboa, conquistando o que quis e não encontrando oposição alguma de D. Fernando, cujo exército havia debandado. Em fevereiro do ano seguinte, Lisboa era em sua maior parte ocupada e o restante, cercada. D. Fernando, vencido e humilhado, apressou-se a firmar um acordo de paz, assinado logo em 24 de março, em Santarém. Entre várias medidas impostas ao derrotado, Portugal ficava obrigado a cortar aliança com os ingleses e unir-se à França e Castela novamente. O que sucede estes eventos é um período de Tesouro exaurido, moeda desvalorizada, elevação de preços e de sofrimento para a população; “[...] o povo revoltava-se contra o rei e contra os tempos [...]", (SOUZA, 1993: 492). Nesse sentido, o soberano embainha a espada inglória e se apega à pena administrativa, no intento de se socorrer; é por este meio que virão 
Cadernos de Clio, Curitiba, n. ${ }^{\circ}$ 3, 2012

seus feitos governativos memoráveis, tais quais o amuralhamento de cidades e vilas, como Lisboa, Porto, Santarém, Braga (13731375); a Lei das Sesmarias, leis protetoras dos mercados nacionais e leis reguladoras dos privilégios jurisdicionais da nobreza (1375) ou, a fundação da Companhia das Naus, em 1380 (SOUZA, 1993).

O recorte cronológico realizado para o presente trabalho inicia-se propriamente em 1378. O desenrolar do mencionado conflito religioso age diretamente na política exterior do reinado de D. Fernando, sobretudo na forma de instrumento de legitimação para ocasionais partidarismos realizados ao longo da Guerra dos Cem Anos. Nesse sentido, é interessante mencionar a colocação de Souza sobre a questão do Cisma, que se irá refletir sobre Portugal:

[...] Um escândalo religioso inominável, por um lado. Por outro lado, porém, um abrir de opções e hipóteses políticas aos condutores dos reinos e nações. Tornara-se possível cristãos combater cristãos, aboletando-se todos no argumento da guerra justa, da guerra religiosa, de ortodoxos contra cismáticos. [...] Útil, excessivamente útil aos príncipes o Grande Cisma do Ocidente. Mudarão de obediência pontifícia ao sabor das oportunidades diplomáticas e políticas. [...] (SOUZA, 1993: 493) 
Cadernos de Clio, Curitiba, n. ${ }^{\text {o } 3,2012}$

Ao longo dos dezesseis anos em que reinou, D. Fernando praticou uma política que foi denominada pela historiografia como "pendular", por seu trânsito entre um e outro bloco. Entretanto, o que caracteriza de maior forma suas atitudes é o fato de em momento algum optar por um partidarismo definitivo. Podemos observar essa questão, a título de exemplo, nos momentos em que D. Fernando declara como legítimo o Papa Clemente VII, apenas por lhe ser conveniente integrar o eixo franco-castelhano ou, ao defender a eleição de Urbano VI quando de sua ambição por forjar uma aliança com a Inglaterra ao prenúncio da terceira guerra travada contra Castela, estando o reino vizinho já sob a égide de D. João I, filho e sucessor de Henrique Trastâmara (BAPTISTA, 1956). Da mesma forma, o conflito religioso atua internamente em Portugal dividindo o clero, a nobreza e outras esferas sociais entre aqueles pró-Avinhão e outros pró-Roma, refletindo-se nos diferentes conselhos recebidos pelo soberano ao longo dos últimos anos de sua regência e que similar à primeira guerra, o conduzirão à terceira contra Castela. Tal partidarismo também não deixará, é claro, de prover benefícios aos defensores da causa, como atestado pelas benesses concedidas a membros da nobreza e do clero (ALMEIDA, 1967).

No âmbito da política exterior, podemos recorrer à Júlio César Baptista, autor que após hercúleo trabalho - principalmente nos arquivos da Cidade do Vaticano - contribuiu ricamente para o 
Cadernos de Clio, Curitiba, n. ${ }^{\circ}$ 3, 2012

desenvolvimento das pesquisas acerca de Portugal e o Cisma do Ocidente $^{5}$. Seu escrito foca principalmente as mudanças de posição portuguesa ao longo do desenrolar do Cisma, assinalando a posição inicial de neutralidade do Reino de acordo com uma tendência semelhante dos demais reinos peninsulares (BAPTISTA, 1956). O significado desta neutralidade religiosa é a solidariedade política, que mostrava-se demasiado conveniente para o reino que liderava a política externa da Península Ibérica: Castela. Henrique Trastâmara, ainda inseguro no trono, ansiava pela paz com seus vizinhos no intento de evitar confrontos externos, dado o fato que internamente, Castela já sofria devido à disputa pela sucessão. Ademais, a própria neutralidade portuguesa seria também com relação à Inglaterra, de modo que acordos haviam se realizado juntamente com os Valois de França por intermédio da Casa de Anjou.

Baptista aponta muito habilmente as idas e vindas de D. Fernando; rompida a neutralidade do Reino em 1381, o soberano português reconhece como legítimo o Papa avinhonês Clemente VII, ambicionando com isso a obtenção de privilégios de interesse geral e benefícios em favor de particulares - em suas palavras, "uns a pedido do rei e outros por nobres e bispos" (BAPTISTA, 1956: 103) - todos concedidos pelo pontífice. Além deste objetivo, o

\footnotetext{
5 Existem muitas lacunas na historiografia com relação a este assunto; observamos, por exemplo, o destaque recebido por D. Pedro I ou D. João I, acabando por eclipsar o período de reinado de D. Fernando.
} 
Cadernos de Clio, Curitiba, n. ${ }^{\text {o }}$ 3, 2012

soberano português procurava tirar vantagem de sua aliança com o bloco francês no intento de fortalecer o reino para uma futura guerra contra Castela - tendo, entretanto, suas ambições arruinadas quando as promessas de aliança franco-portuguesa de 1380 acabam ficando nulas. D. Fernando solicita então a João Fernandes Andeiro (o Conde Andeiro) exilado na Inglaterra, para negociar em Londres a renovação da aliança anglo-portuguesa contra o rei de Castela, sendo que tratados nesse sentido já vinham sendo forjados em segredo muito tempo antes. Estes movimentos políticos resultam na modificação da obediência religiosa, possibilitando-nos destacar ao mesmo tempo a existência do que podemos referenciar como uma "via de mão-dupla": política/religião.

As negociações levadas a cabo pelo Conde Andeiro resultam num acordo anglo-luso selado em Estremoz, em 1380, confirmando, inclusive, o Tratado de Tagilde de 1373. Faz saber-se ao Duque de Lencastre a disposição do soberano português a atacar Castela, agora sob a condução do filho e sucessor de Henrique II, João I; tal momento é conveniente ao reino de Inglaterra por lhe tornar possível concretizar alguns interesses na Península Ibérica: temos a questão dos privilégios marítimos aos ingleses e o próprio Duque, casado com a filha de Pedro I, o Cruel, poderia dessa forma reclamar o trono de Castela. Porém, João I adianta-se e em maio de 1381, tropas castelhanas devastam o Alentejo e Trás-os-Montes - 
Cadernos de Clio, Curitiba, n. ${ }^{\circ}$ 3, 2012

inicia-se a terceira e última guerra que o rei português travará contra o reino vizinho, durando até o ano seguinte, 1382 (SOUZA, 1993).

No presente momento, D. Fernando vê-se completamente ao lado do eixo inglês, sendo que estes lhe propiciam suporte na própria Península Ibérica na forma de tropas auxiliares, chegadas em julho de 1381 e que ficarão estacionadas em Lisboa, partindo para o campo de batalha apenas em dezembro. Neste caso, ao longo de sua campanha, a força inglesa vai conquistando o ódio do povo português, tanto por sua má desenvoltura na guerra, quanto pela série de estragos feitos ao reino, iguais ou piores do que aos efetuados pelo próprio inimigo. $\mathrm{O}$ acontecimento fica ainda mais claro na seguinte passagem do texto de Baptista:

$\mathrm{Na}$ verdade, logo que desembarcaram em Lisboa, os ingleses mais pareceram homens chamados a destruir do que amigos que vinham em ajuda do reino. Matavam, roubavam, profanavam tálamos, defloravam donzelas e praticavam outros excessos, como usam fazer os vencedores em terras conquistadas. Eram inúteis as queixas. O comandante das tropas, a quem cumpria manter a disciplina e corrigir os desmandos, não fazia caso das reclamações. As violências chegaram a tal ponto, que os moradores das terras se viram na necessidade de fazer justiça por suas próprias mãos. Nestas circunstâncias, os aliados tornavam-se indesejáveis; e 
Cadernos de Clio, Curitiba, n. ${ }^{\text {o } 3,2012}$

não admira que o rei procurasse ver-se livre deles. (BAPTISTA, 1956)

No sentido político do conflito, é interessante apontarmos as influências e ações permitidas por este jogo de alianças, onde marca-se a elevação de Castela e seus aliados (ou, "cismáticos"), a pedido do reino de Inglaterra, a um grau similar ao de infiéis, pois usando de sua influência para com Roma e seu Papa, no momento Urbano VI, obteve-se a convocação de uma cruzada contra os apoiadores de Avinhão e colaboradores do Cisma ${ }^{6}$.

Tendo a guerra exigido muito de ambos os lados, secretamente D. Fernando e D. João I Trastâmara estabelecem um acordo de paz $^{7}$ que culmina na retirada dos ingleses, completamente insatisfeitos e frustrados com tal atitude do rei português, além de realizar-se (como obrigação estabelecida pelos contratos de paz) do casamento da infanta portuguesa, D. Beatriz, com o rei de Castela. Este evento denota uma vez mais o entrelaçamento entre as questões políticas e religiosas. Na ocasião, estava em Portugal Pero

\footnotetext{
${ }^{6}$ Tal fato exemplifica-se através das bulas e outros documentos expedidos por Urbano VI, dentre as quais a declaração de que Clemente VII, seus cardeais e partidários estavam excomungados e privados de todas as honras e dignidades. $\mathrm{O}$ duque de Lencastre era nomeado comandante dos exércitos católicos contra Trastâmara e, para aqueles que lutassem ao seu lado, seriam concedidas indulgencias e privilégios que eram dados geralmente àqueles que lutavam na Terra Santa. Com a bula Dudum contra iniquitatis, de 8 de abril, finalmente era proclamada oficialmente a cruzada.

${ }^{7}$ Realizado em agosto de 1382, na cidade de Elvas.
} 
Cadernos de Clio, Curitiba, n. ${ }^{\circ}$ 3, 2012

de Luna, como diplomata do rei de Castela e núncio do Papa de Avinhão; o casamento - realizado em maio de 1383 - seria o caminho mais fácil para estreitar os laços de amizade francocastelhanas com o reino, afastando assim a influência inglesa na Península e ao mesmo tempo, obtendo a imediata declaração de obediência a Avinhão, este sendo o principal objetivo do cardeal (BAPTISTA, 1956).

Após a consumação do ato, D. Fernando percebe o quão desvantajosos poderiam ser os frutos desta união, principalmente no tocante à autonomia do Reino de Portugal - se o rei morresse sem deixar filho varão o trono português seria dado para João I por ocasião da união com D. Beatriz, bem como se esta não the desse um herdeiro. Caso o primogênito de João I tivesse menos de catorze anos à morte de D. Fernando, D. Leonor Teles ficaria como regente até o neto atingir a maioridade - vindo a acontecer isto mas, tomando a história outros rumos. Com isso em mente, novamente abrem-se os diálogos diplomáticos entre Londres e Lisboa no sentido de conseguir um contraponto à amizade castelhana. Ao mesmo tempo, em Santarém realizava-se um conselho onde Pero de Luna $^{8}$ expunha suas teses aos prelados e letrados do reino, em defesa da legitimidade de Clemente VII $^{9}$. O que se sucede, a

\footnotetext{
${ }^{8}$ Que será eleito após a morte de Clemente VII como Bento XIII.

9 Existem discussões acerca da data deste conselho. A "Crônica de D. Fernando", escrita por Fernão Lopes indica o ano de 1381, porém estudos realizados por Baptista, baseando-se no itinerário de D. Fernando e do próprio Pero de Luna,
} 
Cadernos de Clio, Curitiba, n. ${ }^{\text {o }}$ 3, 2012

refutação dos argumentos de Pero de Luna em defesa do papa Urbano VI, uma vez mais mostra o jogo de interesses políticos que perpassa o cisma religioso, sendo oportuno o momento para se atuar pela causa de Roma quando Portugal almeja novamente firmar uma aliança com a Inglaterra. Entretanto, falecendo D. Fernando a 22 de outubro de 1383, inicia-se novo conflito com Castela, desta vez pela disputa sucessória que envolvia o trono português. O resultado disso, em 1385, será a ascensão do meio-irmão do falecido soberano, D. João, Mestre de Avis, que se tornará o primeiro de seu nome ao fundar a Casa de Avis, reinante ao longo da Era Moderna (MARTINS, 1977).

Partindo agora para o âmbito interno do reino, percebemos as reações desencadeadas pelo Cisma, sobretudo na polarização gerada entre os próprios prelados, do qual podemos destacar como de maior relevância o caso ocorrido entre o bispo de Lisboa eleito por Clemente VII, D. Martinho (anteriormente, bispo de Silves) e D. Lourenço, arcebispo de Braga e fiel à causa de Urbano VI.

Por ocasião da vacância do trono do arcebispado de Braga em 1371, D. Martinho seria o escolhido para ocupar seu lugar; entretanto, quem assume a posição de arcebispo é D. Lourenço, eleito ainda pelo papa Gregório XI. Quando tomou posse do

apontam como tendo sido realizado em 1383. Fernandes, em contra partida, insere-se neste debate defende a primeira datação oficial, pautando-se na possibilidade de Pero de Luna ter saído de Medina del Campo e seguido para Santarém ainda em meados de 1381 (BAPTISTA, 1956; FERNANDES, 2007). 
Arcebispado, reinava ali completa desordem, partindo tanto dos próprios clérigos quanto da nobreza que, aproveitando-se do status de padroeiros, violentavam e pilhavam a Sé (ALMEIDA, 1967). D. Lourenço, que estudara Direito em Bolonha e lá fora discípulo de Baldo, iniciou uma grande reforma interna que consequentemente, anulou tais festins, despertando assim a ira da nobreza local, que rapidamente foi queixar-se ao próprio D. Fernando. O soberano então fez-se comunicar a questão ao então pontífice Gregório XI, solicitando a exoneração do arcebispo de seu cargo. Com isso, alguns prelados foram nomeados como visitadores do arcebispado e principalmente, da pessoa do arcebispo: D. Pedro Tenório (bispo de Coimbra e eleito de Toledo), Vasco Domingues, chantre ${ }^{10}$ de Braga e um terceiro, D. Martinho. Em agosto de 1377, ao entraram os visitadores apostólicos em Braga, logo acabam sendo excomungados por D. Lourenço. Tal medida não surtiu efeito, e este precisou abandonar sua sé em 9 de outubro (1377) além de ter destituídos todos os seus bens e rendimentos.

Em face destes problemas, o ex-arcebispo segue para Roma onde havia sido recém eleito Urbano VI, por ocasião da morte de Gregório XI. É feita a apelação ao novo pontífice e este absolve D. Lourenço de todas as acusações, o reintegrando ao arcebispado de Braga (1379). Entretanto, por conta da adesão de D.

\footnotetext{
${ }^{10}$ Título eclesiástico (atualmente extinto) concedido ao mestre do coro ou cantor de Salmos.
} 
Cadernos de Clio, Curitiba, n. ${ }^{\text {o } 3,2012}$

Fernando ao eixo franco-castelhano e o reconhecimento da legitimidade de Clemente VII como Papa legítimo, fica o arcebispo impossibilitado de assumir suas funções, situação que se reverte logo no momento em que o soberano português volta a aderir ao eixo inglês. A partir de então, este atua na corte fernandina como defensor da causa de Roma e de Urbano VI, sobretudo no que tange aos aconselhamentos prestados ao rei.

D. Martinho, frustrado em sua ambição de assumir o arcebispado bracarense, realiza inúmeras solicitações no intento de assumir então a posse da diocese de Lisboa, até que finalmente a consegue por meio do partidarismo de D. Fernando pelo bloco francês e pelo reconhecimento da Sé Apostólica de Avinhão, em janeiro de 1380. Para tanto, o novo bispo atua muitas vezes como emissário dos interesses portugueses em Anjou, na corte dos Valois e da mesma forma, como defensor da causa de Clemente VII dentro da corte de D. Fernando, tal qual D. Lourenço. fornecendo conselhos ao soberano. Com o retorno de D. Fernando ao partidarismo inglês e romano, D. Martinho é privado da diocese de Lisboa mas, reaproxima-se novamente de suas antigas funções ao momento em que finaliza-se a terceira guerra luso-castelhana. Sua morte dá-se de forma violenta, sendo jogado do alto da torre da catedral de Lisboa pela população revoltosa de Lisboa em 1383 que o considerava duplamente traidor, tanto por igualar-se ao lado 
Cadernos de Clio, Curitiba, n. ${ }^{\text {3 } 3,2012}$

castelhano quanto por partidarizar-se ainda com Avinhão, isso simultâneo ao progresso da guerra civil (ALMEIDA, 1967: 380).

Dito isso, é possível perceber o quão intrinsecamente unidos estão o Cisma do Ocidente e a política pendular de D. Fernando, refletindo diretamente na organização e posicionamento religioso interno do reino, levando, a partir disso, as demais sedes episcopais a se posicionarem ou ao lado de D. Lourenço - e a causa de Urbano VI - ou, ao lado de D. Martinho, com o Papa Clemente VII e Avinhão (MARQUES, 1983). Neste sentido, é importante atentarmo-nos a influência do episcopado português (de maneira geral) nas decisões tomadas por D. Fernando; a participação destes nos conselhos reunidos por ele ao longo de seu reinado (e principalmente no período em que se está instalado o Cisma) para se decidir os caminhos e posições a serem tomadas, é muito significativo, sobretudo pelo crédito que D. Fernando dará a suas palavras (não só a deles, mas dos letrados - nesse sentido, ressaltamos o papel de João das Regras, jurista). Podemos destacar a título de exemplo, o próprio e já mencionado Conselho de Santarém. Embora haja o interesse de D. Fernando no direcionamento do resultado deste conselho, a via de mão-dupla que se estabelece entre soberano e clero é perceptível pois ao mesmo tempo que estes dão seu apoio a empresa real, em contrapartida lhes são concedidos favores, convertidos na atribuição de cargos eclesiásticos, benefícios para suas dioceses ou, a si próprios. Não 
Cadernos de Clio, Curitiba, n. ${ }^{\circ}$ 3, 2012

menor é o apoio dado pelos próprios pontífices a seus correligionários, como o suporte oferecido a D. Lourenço após sua destituição do arcebispado de Braga ou, D. Martinho enquanto agia por Avinhão.

Retornando à perspectiva do macro, é interessante nos atermos ao período para melhor visualizarmos e compreendermos os desenlaces ibéricos e principalmente, portugueses no âmbito das dicotomias. Ambos os eixos - inglês e francês - possuíam interesses diversos na Península Ibérica e para tanto, almejavam forjar alianças com os reinos peninsulares a fim de manterem ali uma posição favorável - a neutralidade religiosa estabelecida por Castela e outros reinos peninsulares, nesse sentido, era prejudicial por então não permitir a realização dos interesses tanto francos quanto ingleses. Quando, logo no início do Cisma percebe-se que a atividade inglesa cada vez maior na região era prejudicial, vê-se o maior emprego de ações por parte do rei de França e do duque de Anjou no intento de tornar Portugal, Aragão e Navarra partidários de Avinhão (Castela não se insere nesta lista por conta de sua tradicional fidelidade ao reino de França). Rompida a neutralidade, Portugal procurou consumar uma aliança favorável de acordo com seus interesses, especialmente no que se refere a suas relações com Castela, muito embora tenha que saber lidar com aqueles alheios. Muito além desses jogos políticos e de poder, vemos a marca de tempo sendo impressa no desenrolar dos eventos. O século XIV, 
Cadernos de Clio, Curitiba, n. ${ }^{\circ}$ 3, 2012

além das crises, carrega em si o dom das transformações (como referido anteriormente); as muitas guerras que abarcam o cenário europeu tem como principal característica as disputas sucessórias, sendo este o momento em que veremos o declinar de antigas dinastias que reinaram ao longo do medievo e nascimento de outras; como diz Fernandes,

[...] várias são as ocasiões de crises dinásticas nesse período. Em Portugal, marca-se a transição da dinastia de Borgonha à de Avis. Na França, dos últimos Capetos para os Valois. Em Castela, da Casa de Borgonha para os Trastâmara. Na Inglaterra, dos Plantagenetas para os Lancaster. Em Aragão, da dinastia sicilio-aragonesa. Em Navarra, a consolidação da dinastia dos Evreux. Enfim, um momento de transformação das estruturas, que obriga os monarcas a buscarem consenso interno e apoios externos, a fim de consolidar seu poder. (FERNANDES, 2005: 44-45).

O Cisma do Ocidente, nessa conjectura, servirá como bom instrumento no tocante às justificativas para a firmação de determinadas posições ou mesmo, para legitimar ações realizadas pelos soberanos europeus. No caso português, a relativa estabilidade obtida através de todos os anos da Dinastia de Borgonha, sobretudo por D. Afonso IV (1325-1357) e D. Pedro I (1357-1367) foram 


\section{Cadernos de Clio, Curitiba, n. ${ }^{\circ}$ 3, 2012}

severamente abalados, primeiramente pelos tumultos originados em Castela e posteriormente pelas três guerras luso-castelhanas e o Cisma; sendo assim, D. Fernando não vê outra solução a não ser iniciar sua política pendular. Analisar estes fatos auxiliam sobretudo a originar uma forma diferente de ver a imagem do soberano e de seus atos. De uma forma sintética, podemos ver como recorrentemente o rei é visto pela historiografia:

D. Fernando, emotivo e manobrável, amigo de fidalgos e desdenhador do povo, de Formoso e Inconstante $^{11}$ cognominado, ocupa no painel dos reis portugueses uma posição mal olhada. Desde sempre. O cronista Fernão Lopes dá dele a imagem de um homem que morre chorando, amaldiçoando-se, farrapo de príncipe. E com efeito: coroa dilapidada, trono sem herdeiro, espada vencida, rainha adúltera e nação em perigo" (SOUZA, 1993: 491)

A política de ocasião que reflete-se no posicionamento político e religioso visa principalmente a defesa e alcance de seus interesses, ou em alguns casos, em favor de terceiros em troca de benefícios. Porém, o plano das ações fernandinas visava sobretudo o bem do reino, como a elevação de seu destaque no cenário

\footnotetext{
Tal atribuição, feita no período posterior a sua morte, assume um caráter estritamente pejorativo no sentido de legitimar a recém fundada Casa de Avis em oposição aos anos da de Borgonha e sobretudo, de D. Fernando.
} 
Cadernos de Clio, Curitiba, n. ${ }^{\circ}$ 3, 2012

político ibérico - meta esta observada durante a primeira guerra (1369-1370), quando o trono castelhano e a ampliação do território português era o maior dos objetivos. Numa outra perspectiva, vendo já os últimos esforços, sobressalta-se a tentativa frustrada de evitar a perda de autonomia portuguesa através do direito de sucessão após sua morte. Seguir a fé professada pelo Papa de Roma, ou aquela do de Avinhão era uma questão de estratégia no jogo de interesses que se dava na Península Ibérica. Ao redor dos dois cernes maiores da questão, Inglaterra e França, podemos atestar essa afirmação vendo o momento em que os ingleses, liderados pelo Conde de Cambrige desembarcam em Lisboa (1381) e recusam-se a ouvir a missa ministrada pelos clérigos portugueses, tidos ainda como “cismáticos” pelos ingleses por não ter-se efetuado a nova troca de partidarismo. Vê-se neste caso, um bom instrumento de coerção para D. Fernando transferir sua lealdade para o eixo romano-inglês (BAPTISTA, 1956), dentre tantos outros que vem a se originar.

Como vê-se rotineiramente em obras e demais publicações de maior destaque, a narrativa e a atenção prestada ao recorte cronológico no qual se localiza a Guerra dos Cem Anos centra-se principalmente ao redor das duas potências que estavam em conflito. De igual forma, a questão religiosa que mergulhou a Cristandade latina inteira numa cisão que culminou na própria transformação da Igreja, em poucos casos é visto além âmbito 
Cadernos de Clio, Curitiba, n. ${ }^{\text {o }}$ 3, 2012

franco-inglês. Assim, expandido o tradicional horizonte para outras localidades do continente, em nosso caso chegamos à Península Ibérica e, Portugal. Em parte, a escolha do período fernandino é um reflexo à baixa quantidade de estudos especializados sobre; por outro lado, a escolha possibilita também uma melhor clarificação e compreensão dos fatos expostos, bem como abertura de um caminho para a discussão dos elementos que integram a historiografia referente a este período.

Explorar a questão religiosa no recorte cronológico proposto possibilita enxergá-lo não como um elemento a parte mas, como outro que teve peso na política pendular de D. Fernando. Almejamos com este trabalho, compreender a política pendular do soberano português a partir deste cenário ímpar, onde temos uma Cristandade dividida e conflituosa, acossada sobretudo pelo caos instalado em um de seus pilares morais, a Igreja. Como trata-se de uma época de transformações, vemos o movimento de D. Fernando como a busca por um consentimento interno e externo, sendo que para isso, alterna-se entre a diplomacia e a espada.

Espera-se, portanto, que este trabalho possa demonstrar a importância que teve o Cisma do Ocidente no cenário político português sob a égide de D. Fernando, e a forma que foi utilizada esta cisão como sendo mais um elemento de força no conflito maior que foi a Guerra dos Cem Anos. Fica claro com isso que as formações de aliança não estavam necessariamente ligadas a 
Cadernos de Clio, Curitiba, n. ${ }^{\circ}$ 3, 2012

idealismos ou mesmo, conexões por uma mesma fé mas sim, encontram-se permeadas pelos interesses de grupos sociais que utilizam-se dos meios que lhes são disponíveis para alcançar seus objetivos. Assim o fez D. Fernando frente ao vizinho castelhano, frente ao seu próprio reino, e frente aos demais conflitos e eventos que se desenhavam no horizonte ibérico.

\section{Bibliografia:}

ALMEIDA, Fortunato de. História da Igreja em Portugal (ed. de Damião Peres). Porto: Portucalense Editora, 1967, vol. I, pp. 37481.

BAPTISTA, J. César. Portugal e o Cisma do Ocidente, in: Lusitania Sacra, Lisboa, ${ }^{\circ} 1$ (1956), pp. 65-179.

FERNANDES, Fátima R. A política fernandina na Baixa Idade Média portuguesa, in: Revista de História da UPIS, 2005, vol. I, pp. 43-60.

FERNANDES, Fátima R. O reinado fernandino sob a ótica das relações régio-nobiliárquicas, in: Poder e sociedade (Actas das jornadas interdisciplinares) vol. I, Lisboa: Universidade Aberta, 1998.

FERNANDES, Fátima R. A monarquia portuguesa e o Cisma do Ocidente (1378-85), in: Instituições, Poderes e Jurisdições, org. 
Cadernos de Clio, Curitiba, n. ${ }^{\circ}$ 3, 2012

Renan FRIGHETTO e Marcella Lopes GUIMARÃES, Curitiba: Juruá, 2007, pp. 137-56.

KNOWLES, David e OBOLENSKY, Dimitri. Nova História da Igreja. Petrópolis: Vozes, 1983, vol. II, pp. 445-456.

MARQUES, A. H. de Oliveira. História de Portugal desde os tempos mais antigos até a presidência do Sr. General Eanes: manual para uso de estudante e outros curiosos por assuntos do passado pátrio. Lisboa: Palas Editores, 1983, vol. I, pp. 207-233. MARTINS, Oliveira. Historia de Portugal. $17^{\mathrm{a}}$ ed. Lisboa: Guimarães Editores, 1977. pp. 65-158.

PEDRERO-SÁNCHEZ, Maria Guadalupe. História da Idade Média: textos e testemunhas. São Paulo: Editora UNESP, 2000. pp. 193-211.

SOUZA, Armindo de. "1325-1480". In: MATTOSO, José (dir.). História de Portugal: A Monarquia Feudal (vol. II, 10961480). Lisboa: Editorial Estampa, 1993, pp. 490-494. 